\title{
Optimal Stochastic Pine Stands Harvest Rotation Policies
}

\author{
Eduardo Navarrete \\ Department of System Engineering, Universidad de la Frontera, Temuco, Chile \\ Email: eduardo.navarrete@ufrontera.cl
}

Received 15 May 2015; accepted 1 August 2015; published 6 August 2015

Copyright (C) 2015 by author and Scientific Research Publishing Inc.

This work is licensed under the Creative Commons Attribution International License (CC BY). http://creativecommons.org/licenses/by/4.0/

\section{c) (i) Open Access}

\begin{abstract}
A new Faustmann optimal rotation harvesting stands' problem under Brown geometric price and Logistic and Gompertz wood stock, diffusions is presented. The optimal cut policies for the stochastic Faustmann model and the single harvest rotation or Vicksell model are evaluated in the case of a Chilean Radiata pine forest company. The company cut policy validates the Vicksell model, its optimal cut policies overestimate the company policy cut in $1.2 \%$, in the Gompertz case, and underestimate it in $2.3 \%$, in the Logistic case. The Faustmann optimal cut policies present a larger underestimation of the company cut policy in $10.1 \%$, in the Gompertz case, and in $21.5 \%$, in the Logistic case. The preference for shorter evaluation period that the company shows is due to the organizational risk that the forest economic sectors has in Chile.
\end{abstract}

\section{Keywords}

Optimal Tree Cutting, Faustmann Stochastic Formula Component, Optimal Stopping Problem

\section{Introduction}

The optimal forest harvest models development is marked by the emergence of two controversial issues. The first issue was formulated in its early beginning by Faustmann in 1849. He formulated a multiple rotation version considering the dynamic effect that the future renovations had in the rotation period of the cut and planting of the trees. The issue was not considered relevant by researchers and forester management, who preferred a simple rotation or Vicksell model. The Faustmann model was finally rediscovered, first by Gaffney in 1957, and finally by Samuelson in 1976, who validated Faustmann's deterministic formula as the correct one, since it was the only one to consider the cost of land rent. An increasing number of researchers continued extending this model (Brazee, 2001; Chang, 2001; Amacher et al., 2011). The second issue was strongly formulated by Samuelson (1976), calling to replace the simple notion of stationary equilibrium by the notion of perpetual Brownian motion of wood price. Many researchers followed his recommendation and considered the single rotation prob- 
lem as an American call option, taking into account wood price as a geometric Brown diffusion (see, Newman, 2002; Clarke \& Reed, 1989; Thomson, 1992; Platinga et al., 1998). Other authors also considered the wood stock as a second geometric Brown diffusion (Morck \& Schwartz, 1989; Insley, 2002), or as a Logistic diffusion (Alvarez \& Koskela, 2007; Navarrete, 2011). Willassen (1998) introduced uncertainty to the Faustmann model, incorporating the forest growth as a stochastic Markov diffusion process and characterizing the properties of the optimal solutions. Sodal (2002) simplified Willassen's approach in a closed-form rotation formula for the same state stochastic variable and Insley \& Rollins (2005) proposed a numeric algorithm to solve its Hamilton-JacobiBellman solution. Navarrete \& Bustos (2013) extended the Faustmann model considering, price as a geometric Brown and wood stock as a Logistical or Gompertz, diffusions processes, transforming the model into an equivalent optimal stopping problem, in spite of its contribution. This paper requires some improvement which will be done in the present paper. Therefore this paper has two basic objectives. In section 2.3, the proof of the equivalence of the Faustmann rotation model under Brown Price and ITO wood stock independent diffusion processes and a one dimensional modified wood stock Optimal Stopping problem is formalized as a reformulation lemma. In section 4, a new algorithm is developed to obtain the Faustmann equivalent one dimensional optimal stopping solution, intersecting the optimal condition curve with the expected wood stock growth feasibility restriction. Finally new stands growth data for the middle age 11 and 12 years is incorporated in Section 3, in order to validate Vicksell and Faustmann stands cut models, under price and wood stock uncertainty.

\section{Stochastic Harvest Models}

\subsection{Stochastic Harvest Stands Rotation Models}

The basic model considers two independent stochastic processes: an ITO diffusion for the wood stock, Equation (1) and a geometric Brownian diffusion, Equation (2). The functional objective for the single rotation is given by Equation (3) and for the multiple rotations by Equation (4) see Johnson (2006):

$$
\begin{gathered}
\mathrm{d} V_{t}=\mu\left(V_{t}\right) \mathrm{d} t+\sigma\left(V_{t}\right) \mathrm{d} W_{V} \\
\mathrm{~d} P_{t}=\alpha P_{t} \mathrm{~d} t+\beta P_{t} \mathrm{~d} W_{P} \\
F^{s}(\bar{V}, T)=\sup _{\forall(t \geq 0)}\left[E_{(V, P)}^{R}\left(\mathrm{e}^{-i t} P_{t} V_{t}-C\right)\right] \\
F^{M}(\bar{V}, T)=\sup _{\forall(t \geq 0)}\left[E_{(V, P)}^{R} \frac{\left(\mathrm{e}^{-i t} P_{t} V_{t}-C\right)}{\left(1-\mathrm{e}^{-i t}\right)}\right]
\end{gathered}
$$

Model notation:

\section{Deterministic state variable}

$t=$ Wood stock age

Stochastic sate variables

$V_{t}=$ Wood stock

$P_{t}=$ Wood stumpage price at time $\mathrm{t}$

Diffusion Parameters

$W_{v}=$ Wiener wood stock

$\mu(V)=$ Wood stock diffusion drift rate parameter

$\sigma(V)=$ Wood stock volatility parameter

$W_{p}=$ Wiener price

$\alpha=$ Wood price diffusion drift rate

$\beta=$ Wood price volatility

$$
\begin{aligned}
& \text { Economic Parameter } \\
& C=\text { Stand regeneration cost } \\
& P_{0}=\text { Price at time } 0 \\
& C=C / P_{0} \\
& R, Q=\text { Probabilistic metrics } \\
& F, Z=\text { Functional objective } \\
& i=\text { Risky rate of return } \\
& r_{T}=i /\left(1-\mathrm{e}^{-i T}\right), \text { Capitalized rate of return } \\
& \text { Optimal Parameters } \\
& T=\text { Optimal cut time } \\
& \bar{V}=\text { Expected optimal cut volume }
\end{aligned}
$$

\subsection{Reformulation of the Simple Harvest Rotation Problem}

The stochastic model (1) (2) and (3) is difficult to solve due to both diffusions. But it is equivalent to the following one dimensional diffusion Optimal Stopping problem, (5) and (6) see Navarrete (2011). 


$$
\begin{aligned}
& Z^{S}(\bar{V}, T)=\sup _{\forall(t \geq 0)}\left[E_{\left(V_{t}\right)}^{Q}\left(\mathrm{e}^{-(i-\alpha) t} V_{t}-c\right)\right] \\
& \mathrm{d} V_{t}=\left[\mu\left(V_{t}\right)+\beta \sigma\left(V_{t}\right)\right] \mathrm{d} t+\sigma\left(V_{t}\right) \mathrm{d} \bar{W}_{V}
\end{aligned}
$$

The solution of this problem is given by the (HJB) Equation (7), see Navarrete (2011).

$$
\operatorname{Max}_{\bar{V} \geq 0}\left\{\left(\frac{1}{2}\right) \sigma^{2} \bar{V}^{2} F^{\prime \prime}(\bar{V})+[\mu(\bar{V})+\beta \sigma(\bar{V})] F^{\prime}(\bar{V})-(i-\alpha) F(\bar{V}), \bar{V}-F(\bar{V})\right\}=0
$$

Assuming the existence of a frontier $V^{*}$ that divides the zone into a continuation zone (no-cutting) and a stopping zone (immediate-cutting), the solution to the equation HJB is given by (8) for the continuation zone (8) and stopping zone (9). A solution of (8) is given by (10) (see Johnson, 2006).

$$
\begin{gathered}
\left(\frac{1}{2}\right) \sigma^{2} \bar{V}^{2} F^{\prime \prime}(\bar{V})+[\mu(\bar{V})+\beta \sigma(\bar{V})] F^{\prime}(\bar{V})-(i-\alpha) F(\bar{V})=0 \\
\bar{V}-F(\bar{V})=0 \\
F(\bar{V})= \begin{cases}A \Psi(\bar{V})+B \Phi(\bar{V}) & \bar{V}<V^{*} \\
\bar{V} & \bar{V} \geq V^{*}\end{cases}
\end{gathered}
$$

where $\Psi$ (resp., $\Phi$ ) is strictly increasing (resp., decreasing), function since the payoff function are bounded and small, $V$ is positive and should remain bounded and positive a $V \rightarrow 0$, necessarily then $B \rightarrow 0$. The solution also fulfils the smooth-pasting condition at the free boundary point $V^{*}$, equations (11) and eliminating the constant $A$ gives Equation (12).

$$
\begin{gathered}
A \Psi(\bar{V})=\bar{V} \text { and } A \Psi^{\prime}(\bar{V})=1 \\
\Psi(\bar{V})=\bar{V} \Psi^{\prime}(\bar{V}) .
\end{gathered}
$$

\subsection{Reformulation of the Multiple Harvest Rotation Problems}

The Faustmann optimal rotation model (1) (2) and (4) its equivalent to the following Optimal Stopping one dimensional diffusion problem (13) and (14), see Lemma 1.

Lemma 1. Reformulation Lemma:

The Faustmann optimal rotation problem is equivalent to the following Optimal Stopping one dimensional diffusion problem (13) and (14).

$$
\begin{gathered}
Z^{M}(\bar{V}, T)=\sup _{\forall(t \geq 0)} E_{V}^{Q} \frac{\left(\mathrm{e}^{-(i-\alpha) t} V_{t}-c\right)}{\left(1-\mathrm{e}^{-i t}\right)} \\
\mathrm{d} V_{t}=\left\{\mu\left(V_{t}\right)+\beta \sigma\left(V_{t}\right)\right\} \mathrm{d} t+\sigma\left(V_{t}\right) \mathrm{d} \bar{W}
\end{gathered}
$$

\section{Proof:}

Given the independence of both variables the expectation can be calculated as the product of two independent expectation " $E_{\left(V_{t}\right)}^{R} E_{\left(V_{t}\right)}^{R}$ " that are independent of the deterministic parameters $\mathrm{e}^{-i t}$ and $1 /\left(1-\mathrm{e}^{-i t}\right)$ and the constant $C$, so they can be taken outside its domain. Introducing the integration of the price Brown diffusion $P_{t}=P_{0} \mathrm{e}^{\alpha t} M_{t}$ with $M_{t}=\exp \left(\beta W p-1 / 2 \beta^{2} t\right)$ and $C=P_{0} C$ in the functional objective (4) results in the objective (15) and reduce the Faustmann problem to the following one dimensional diffusion problem (15) and (16).

$$
\begin{gathered}
F^{M}(\bar{V}, T)=P_{o} \sup _{\forall(t \geq 0)}\left\{\frac{1}{\left(1-\mathrm{e}^{-i t}\right)}\left[E_{V_{t}}^{R}\left\{E_{P_{t}}^{R}\left(\mathrm{e}^{-(i-\alpha t)} M_{t} V_{t}-c\right)\right\}\right]\right\} \\
\mathrm{d} V_{t}=\mu\left(V_{t}\right) \mathrm{d} t+\sigma\left(V_{t}\right) \mathrm{d} W_{V}
\end{gathered}
$$

Dividing the objective functional (15) by the constant $P_{0}$ and applying the Thijssen version of the Girsanov 
theorem to Equations (15) and (16), for the Martingale $M_{t}$ and the Radom-Nykodym derivative $\mathrm{d} R / \mathrm{d} Q=M_{t}$ (see Thijssen, 2010, Appendix A) permits to reformulate the problem (13) (14) by its equivalent $Q$ metric optimal stopping problem (16) and (17).

The formulation of the HJB equation for this problem is given by Equation (17) for the capitalized risky rate of return $r_{T}=i /\left(1-\mathrm{e}^{-i T}\right)$ see Navarrete \& Bustos (2013).

$$
\operatorname{Max}_{\bar{V} \geq 0}\left\{\left(\frac{1}{2}\right) \sigma^{2} \overline{V^{2}} F^{\prime \prime}(\bar{V})+\left[\mu(\bar{V})+\beta \sigma\left(V_{t}\right)\right] F^{\prime}(\bar{V})-\left(r_{T}-\alpha\right) F(\bar{V})-c r_{T}, \frac{(\bar{V}-c)}{1-\mathrm{e}^{-i T}}-F(\bar{V})\right\}
$$

In this case the differential equation for the continuation region $\left(\bar{V} \leq V^{*}\right)$ is given by the non homogenous differential Equation (18), and by Equation (19) for the stopping zone $\bar{V}\left(>V^{*}\right)$.

$$
\begin{gathered}
\left(\frac{1}{2}\right) \sigma^{2} \overline{V^{2}} F^{\prime \prime}(\bar{V})+\left[\mu(\bar{V})+\beta \sigma\left(V_{t}\right)\right] F^{\prime}(\bar{V})-\left(r_{T}-\alpha\right) F(\bar{V})-c r_{T}=0 ; \text { with, } F(0)=\frac{r_{T}}{i} c \\
\frac{\bar{V}-c}{\left(1-\mathrm{e}^{-i T}\right)}-F(\bar{V})=0
\end{gathered}
$$

The solution to the ordinary differential equation, (18) under the initial condition for a given risky rate of return $r_{T}$ is given in Equation (20), with $\psi(\bar{V})$, the positive increasing solution of the homogenous part and $\left[r_{T} / i\right] c$ the particular solution of Equation (18).

$$
F(\bar{V})= \begin{cases}A \Psi(\bar{V})-\frac{r_{T}}{i} c & \bar{V}<V^{*} \\ \bar{V} & \bar{V} \geq V^{*}\end{cases}
$$

In this case the smooth pasting condition for each parameter $r_{T}$ are given by Equation (21):

$$
A \Psi(\bar{V})-\frac{r_{T}}{i} c=\frac{\bar{V}-c}{\left(1-\mathrm{e}^{-i T}\right)}=\frac{r_{T}}{i}(\bar{V}-c), \quad A \Psi^{\prime}(\bar{V})=\frac{r_{T}}{i}
$$

So $\bar{V}$ must fulfill smooth-pasting condition (22) for each parameter $r_{T}$.

$$
\Psi(\bar{V})=\bar{V} \Psi^{\prime}(\bar{V})
$$

\subsection{Wood Stock Sigmoid Diffusion Equations}

The basic requirement of a pine stand growing diffusion is its sigmoid pattern (Garcia, 2005). The logistic diffusion, Equation (23) is a special case of the sigmoid model given by $\mu(V)=\mu V(1-\gamma V)$ and $\sigma(V)=\sigma V$, where $\mu$ and $\gamma$ are the drift and saturation parameters and $\sigma$ is the volatility parameter.

$$
\mathrm{d} V_{t}=\mu V_{t}\left(1-\gamma V_{t}\right) \mathrm{d} t+\sigma V_{t} \mathrm{~d} W_{V}
$$

The integration of the value of $V$ is given by Equation (24) (Kloeden \& Platen, 1992: p. 125) and its expected value is given by Equation (25)

$$
\begin{gathered}
V_{t}=\frac{V_{0} \operatorname{Exp}\left[\left(\mu-\frac{\sigma^{2}}{2}\right) t+\sigma W\right]}{1+\mu \gamma V_{0} \int_{t_{m}}^{t} \operatorname{Exp}\left[\left(\mu-\frac{\sigma^{2}}{2}\right) s+\sigma W\right] \mathrm{d} s} \\
E\left(V_{t}\right)=\frac{\frac{1}{\gamma}}{1+\frac{1-\gamma V_{0}}{\gamma V_{0}} \mathrm{e}^{-\mu t}}
\end{gathered}
$$

Other important sigmoid diffusion is the Gompertz geometrical diffusion, which is given by Equation (26), 
which is integrated to the expression (27), and its expected values given by expression (28) (see Gutierrez, 2009).

$$
\begin{gathered}
\mathrm{d} V_{t}=k V_{t}\left[\theta-\ln \left(V_{t}\right)\right] \mathrm{d} t+\sigma V_{t} \mathrm{~d} W_{V} \\
V_{t}=\exp \left\{\ln \left(V_{0}\right) \mathrm{e}^{-k t}+\left[\theta-\frac{\sigma^{2}}{2 k}\right]\left(1-\mathrm{e}^{-k t}\right)+\sigma \mathrm{e}^{-k t} \int \mathrm{d} W_{V}\right\} \\
E\left(V_{t}\right)=\exp \left\{\ln \left(V_{0}\right) \mathrm{e}^{-k t}+\left[\theta-\frac{\sigma^{2}}{2 k}\right]\left(1-\mathrm{e}^{-k t}\right)+\frac{\sigma^{2}}{4 k}\left(1-\mathrm{e}^{-2 k t}\right)\right\}
\end{gathered}
$$

The Geometric Brown Price diffusion is given by Equation (29), and integrates in Equation (30).

$$
\begin{gathered}
\mathrm{d} P_{t}=\alpha P_{t} \mathrm{~d} t+\beta P_{t} \mathrm{~d} W_{P} \\
P_{t}=P_{0} \mathrm{e}^{\alpha t} \exp \left(\beta W_{P}-\frac{1}{2} \beta^{2} t\right)
\end{gathered}
$$

\section{Experimental Data and Parameter Fitting}

\subsection{Logistic Diffusion Fitting}

The experimental data belonged to 122 harvest pine stands of a Chilean Forest Company in the Araucania Chile region, between years 1999 and 2005 (see Appendix A), and came from different sample plots, with site indexes between 30 and 35 meters, representing sites with high forest aptitude and a tree average initial volume of $32 \mathrm{~m}^{3} /$ ha at the first 4 years after initial seed cultivation period. The additional 20 point for years 11 and 12 were taken from Alvarez et al. (2012). The business harvest cut data for a Logistic diffusion for the $95 \%$ confidence range is given by data point plotted in Figure 1.

The logistic diffusion parameter cannot be adjusted by maximum verisimilitude, see (Beskos et al., 2006), so it was fitted using a logistical nonlinear regression and a Monte Carlo/Bootstrap simulation sampling method, implemented by Meyer et al. (Loglet Lab.1 software, 1999). Choosing $V_{0}=1 / 2 \gamma=$ half saturation volume, and $T_{0}=T_{m}$, time to achieve that volume, Equation (25) is transformed into the more conventional expression (31).

RADIATA PINE STANDS (30/35)

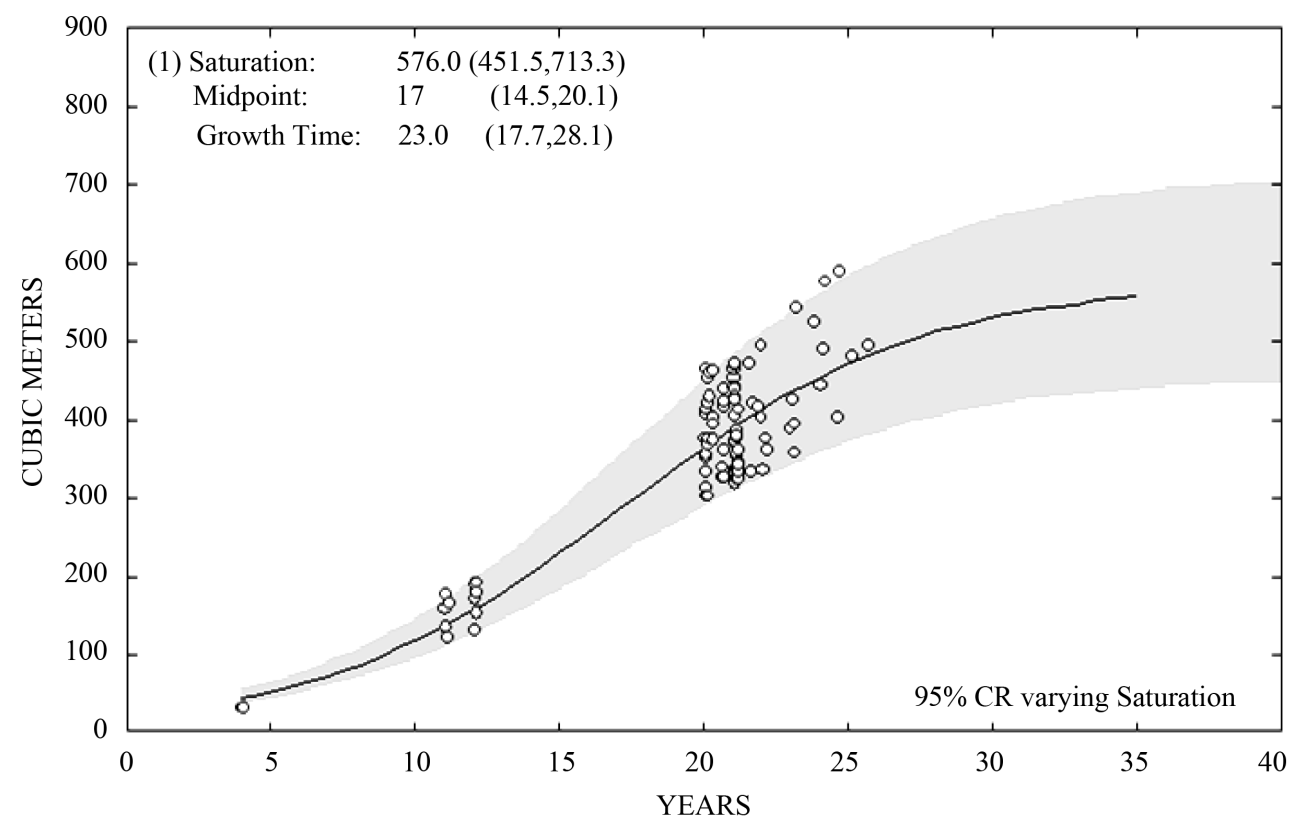

Figure 1 . Wood volume per hectare, $\left(\mathrm{m}^{3} / \mathrm{ha}\right)$ versus years. 


$$
E\left(V_{t}\right)=\frac{1 / \gamma}{1+\mathrm{e}^{-\mu\left(t-t_{m}\right)}}
$$

With; $1 / \gamma=$ saturation volume, $\mu$ = growth rate parameter, $V_{s}=$ Saturation volume and $t_{m}=$ time to achieve the midpoint of the saturation volume. The standard deviation $S d(\infty)$, at the saturation zone is constant, and given by Equation (32).

$$
S d(\infty)=\sigma V_{s}=(95 \% \text { saturation confidence interval }) /(2 \times 1.96)
$$

Since the saturation volume $V_{s}$ is also constant, sigma can easily be estimated by Equation (33) and the summary of the parameter fitting is shown in Table 1.

$$
\sigma=S d(\infty) / V_{s}
$$

\subsection{Gompertz Diffusion Fitting}

The Gompertz model can be fitted by common statistic features, such as maximum verisimilitude (see Gutierrez et al., 2008), but the lack of equal time distribution of data make it difficult. So a quadratic fitting method was development using the SSPS software. By taking natural logarithm and arranging it we get Equation (34).

$$
\ln E\left[V_{t}\right]=A-B x-C x^{2}
$$

$$
\text { with } A=\theta-\sigma^{2} /(4 k), B=\theta-\sigma^{2} /(2 k)-\ln \left(V_{0}\right), C=\sigma^{2} /(4 k) \text { and } x=\mathrm{e}^{-k t}
$$

Given a value for $k$, a quadratic fitting for $\mathrm{e}^{-k t}$ and $\mathrm{e}^{-2 k t}$ was done estimating the value of $A, B$ and $C$ until a common value for $\theta$ was obtained from $A$ and $B$, determining the estimation for $\theta, k$ and $\sigma$. The deterministic parameter only requires a linear fitting with $\mathrm{e}^{-k t}$. Both fittings were done for the initial value $V_{0}=32\left(\mathrm{~m}^{3} / \mathrm{ha}\right)$ and the results are summarized in Table 2.

\subsection{Wood Price Diffusion Fitting Equations and Regeneration Costs}

The stumpage stand price Brownian diffusion parameters are estimated from saw logs and pulp logs exportation prices (see Appendix B). The summary of Brown diffusion parameters for the stumpage price and the regeneration cost of radiata Pine Stands are given in Table 3, see Navarrete \& Bustos (2013).

\section{Stochastic Optimal Pine Harvestings Results}

\subsection{Logistic Wood Stock and Brown Stumpage Price models}

The deterministic optimal solution given by $V^{*}=(\alpha+\mu-i) /(\gamma \mu)$, for the simple rotation model and by equation (36) for the multiple rotation model, see Navarrete (2013).

Table 1. Logistic fitting parameters.

\begin{tabular}{ccccc}
\hline Models & $\begin{array}{c}\text { Drift } \\
\text { Parameter } \mu\end{array}$ & $\begin{array}{c}\text { Saturation } \\
\text { Volume }\end{array}$ & Saturation Parameter $\gamma$ & Volatility Parameter $\sigma$ \\
\hline Stochastic & 0.191 & 576.0 & 0.00174 & 0.12 \\
Deterministic & 0.191 & 576.0 & 0.00174 & \\
\hline
\end{tabular}

Table 2. Gompertz diffusions parameters estimations.

\begin{tabular}{cccccc}
\hline Parameters & Saturation & Drift & Drift & Volatility \\
Models & $V_{s}$ & $k$ & $\Theta$ & $\sigma$ & 0.151 \\
Gompertz & 653.3 & 0.102 & 6.538 & 0.992 \\
Deterministic & 653.3 & 0.102 & 6.538 & \\
\hline
\end{tabular}


Table 3. Radiata pine price diffusion parameters and capital and regeneration stands costs.

\begin{tabular}{ccc}
\hline Price stumpage drift & $\alpha$ & $2.9 \%$ \\
Price stumpage volatility & $\beta$ & $15.9 \%$ \\
Actual stumpage log price & $P_{T}$ & $39.74 \mathrm{US} \$ / \mathrm{ha}$ \\
Initial stumpage price & $P_{0}$ & $21.43 \mathrm{US} \$ / \mathrm{ha}$ \\
Risky rate of Capital & WACC & $12 \%$ \\
Stands regeneration cost & $C$ & $882 \mathrm{US} \$ / \mathrm{ha}$ \\
Stands cost per unit initial price & $c=C / P_{0}$ & 41.16 \\
\hline
\end{tabular}

Source: Appendix B.

$$
V^{*}=\frac{\left(\alpha+\mu-r_{t}\right)+\sqrt{\left(\alpha+\mu-r_{t}\right)^{2}+4 \mu \gamma c r_{t} \mathrm{e}^{-\alpha t}}}{2 \mu \gamma}
$$

The solution of the Vicksell and Faustmann model under Brown price and Logistic wood stock diffusion requires the solution of the differential Equations (8) and (19) for $\mu(V)=\mu V(1-\gamma V)$ and $\sigma(V)=\sigma V$. The positive increasing function $\psi(V)$ for the Vicksell model, is the solution of the homogenous component (37) of the differential Equation (8) with $r_{T}=i$ in the Vicksell case.

The solution of Equation (37) is given by the Kummer's confluent hyper geometric function, expression (38) with the positive root $\theta$ by Equation (39), $\psi(V)$ also must fulfill the smooth pasting condition (12), which was programmed in Mapple 15, see Navarrete (2013).

$$
\begin{gathered}
\left(\frac{1}{2}\right) \sigma^{2} \overline{V^{2}} F^{\prime \prime}(\bar{V})+[\mu \bar{V}(1-\gamma \bar{V})+\beta \sigma \bar{V}] F^{\prime}(\bar{V})-\left(r_{T}-\alpha\right) F(\bar{V})=0 \\
\Psi(\bar{V})=V^{\theta} \text { KummerM }\left\{\frac{2 \mu \gamma \bar{V}}{\sigma^{2}}, \theta, 2 \theta+\frac{2(\mu+\beta \sigma)}{\sigma^{2}}\right\} \\
\theta=\frac{1}{2}-\frac{\mu}{\sigma^{2}}-\frac{\beta}{\sigma}+\sqrt{\left(\frac{1}{2}-\frac{\mu}{\sigma^{2}}-\frac{\beta}{\sigma}\right)^{2}+\frac{2\left(r_{T}-\alpha\right)}{\sigma^{2}}}
\end{gathered}
$$

The Faustmann stochastic optimum requires the solution of the differential Equation (16), so the positive function $\psi(V)$ is the solution of its homogenous Equation (37) for the parameter $r_{T}$ and also fulfill the smooth pasting condition, (22). For a given value of the capitalized interest $r_{T}=i /\left(1-\mathrm{e}^{-i T}\right)$ Equation (37) can be solved using the same methodology of the Vicksell solution, generating a family of optimal cuts for the different parameters $r_{T}$. The optimum solution is obtained intersecting the optimal parametric solution for different $T$ with the corresponding expected value logistical modify diffusion, (14) for $\bar{V}$, see Figure 2 . The summary of all optimal cuts results for the aggregate 30/35 site index series of the multiple and simple rotation harvest model under Brown price and Logistic wood stock diffusions is given in Table 4.

The simple optimal cut is a better explanation of the company cut policy, since it only underestimates it in a $2.5 \%$. As expected the Faustmann optimal cut is lower and underestimate the company policy in $11.5 \%$. The deterministic optimal cuts are even worse and underestimate the company policy in $23.4 \%$ in the simple model and in $25.6 \%$ in the multiple cases. Finally the Logistic wood stock underestimates the saturation Volume in $4.2 \%$.

\subsection{Gompertz Wood Stock and Brown Stumpage Price Case}

The deterministic optimal solution, is given by $V^{*}=\mathrm{e}^{(\alpha+k \theta-i) / k}$ for the simple rotation model and for Equation (41) for the multiple rotation case the optimal is obtained intercepting condition (40) with Equation (27). See Navarrete (2013).

$$
\ln (V)=\frac{\left(\alpha+k \theta-r_{T}\right)}{k}+\frac{r_{T} c \mathrm{e}^{-\alpha t}}{k V}
$$




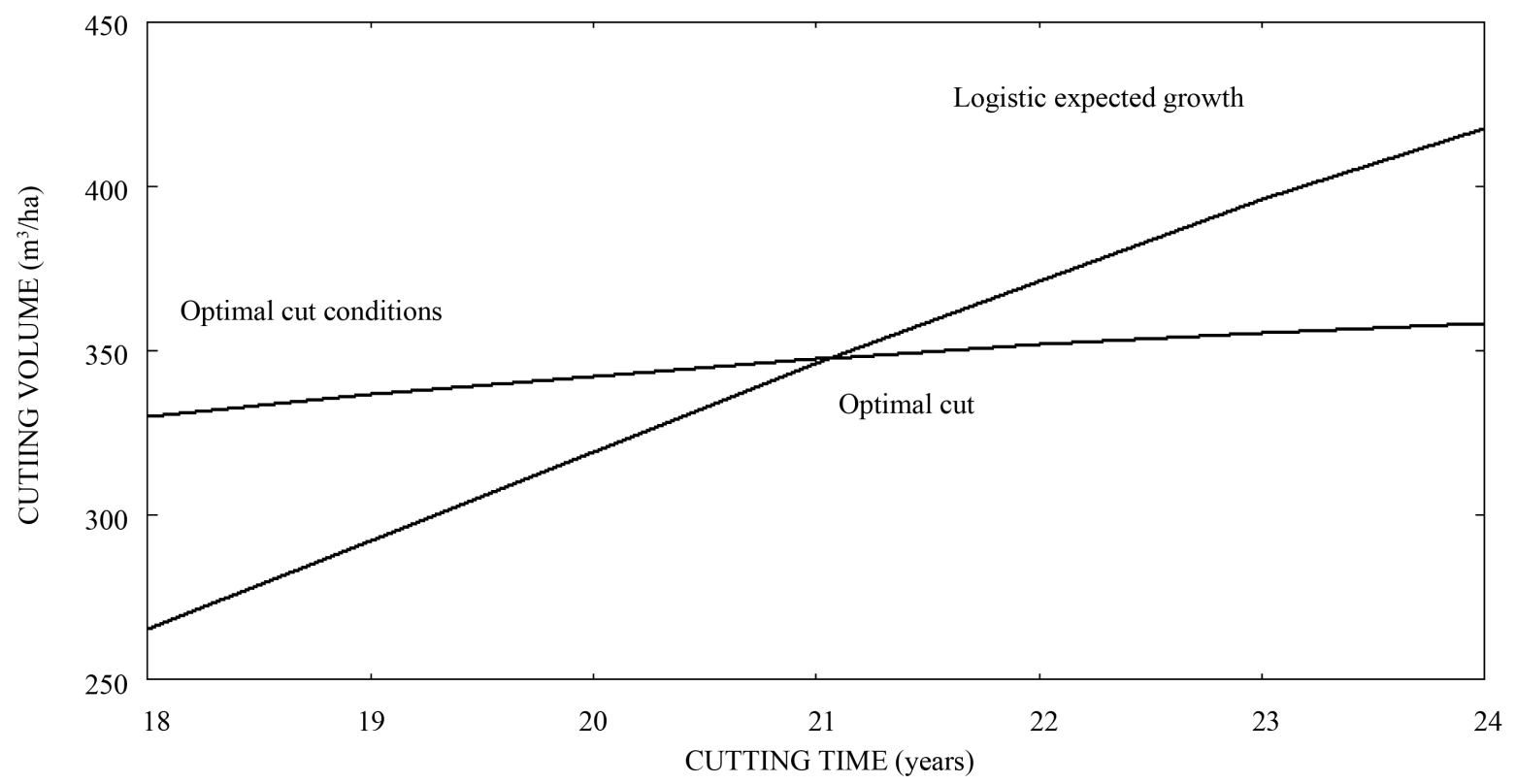

Figure 2. Faustmann logistic optimal cut.

Table 4. Optimal harvest rotation optimal results, Brown price logistic wood stock diffusion.

\begin{tabular}{ccccccc}
\hline Optimum Policy & $\begin{array}{c}\text { Simple } \\
\mathrm{m}^{3} / \mathrm{ha}\end{array}$ & Harvest \% & Multiple $\mathrm{m}^{3} / \mathrm{ha}$ & Harvest \% & $\begin{array}{c}\text { Saturation } \\
\mathrm{m}^{3} / \text { ha }\end{array}$ & Volume \% \\
\hline Company & 392.9 & 100.0 & 392.9 & 100.0 & 601.6 & 100 \\
Deterministic & 300.9 & -23.4 & 292.3 & -25.6 & & 576 \\
Stochastic & 383.1 & -2.5 & 347.6 & -11.5 & -4.3 \\
\hline
\end{tabular}

The solution of the Vicksell and Faustmann model under Brown price and Gompertz wood stock diffusion requires the solution of the differential Equations, (8) and (16) for $\mu(V)=k V(\theta-\ln V)$ and $\sigma(V)=\sigma V$. The stochastic increasing function $\psi(V)$, for these cases is given by the solution of the homogenous Equation (41) with $r_{T}=i$ for the simple rotation case and the capitalized rate of interest $r_{T}$ for the Faustmann case.

$$
\left(\frac{1}{2}\right) \sigma^{2} \bar{V}^{2} F^{\prime \prime}(\bar{V})+[k \bar{V}(\theta-\ln (\bar{V}))+\beta \sigma \bar{V}] F^{\prime}(\bar{V})-\left(r_{T}-\alpha\right) F(\bar{V})=0
$$

Replacing the parameters given in Equations (42) in (41), gives the differential Equation (43) of the Exponential, Ornstein-Uhlembeck diffusion whose positive increasing solution $\psi(V)$ is given by Equation (44) (see Johnson, 2005), with: $a=(r-\alpha) /(2 k), b=0.5$ and $z=\left(k / \sigma^{2}\right)\left[\theta-\sigma^{2} /(2 k)+\beta \sigma / k-\ln (V)\right]$

$$
\begin{gathered}
\bar{\theta}=\theta-\frac{\sigma^{2}}{2 k}+\frac{\beta \sigma}{k}, \quad \overline{r_{T}}=r_{T}-\alpha \\
\left(\frac{1}{2}\right) \sigma^{2} \bar{V}^{2} F^{\prime \prime}(\bar{V})+\left[k(\bar{\theta}-\ln (\bar{V}))+\frac{1}{2} \sigma^{2}\right] \bar{V} F^{\prime}(\bar{V})-\overline{r_{T}} F(\bar{V})=0 \\
\Psi(\bar{V})= \begin{cases}{[\Gamma(a+1-b) / \Gamma(1-b)] \operatorname{Kummer} U(a, b, z)} & \bar{V} \leq \mathrm{e}^{\theta} \\
\operatorname{Kummer} M(a, b, z) & \bar{V} \geq \mathrm{e}^{\theta}\end{cases}
\end{gathered}
$$

The optimal solutions also requires that $\psi(V)$ fulfills the smooth pasting condition (38), which is programmed in Mapple 15 generating one optimal cut solution for the Vicksell model and a family of optimal cut condition parametrized by $T$ for the Faustmann case. In this late case the optimal solution is obtain intercepting the family with the expected volume of the Gompertz modify diffusion (20), see Figure 3. 
The deterministic and stochastic optimum were programed in Maple 15, using in this case the KummerU function of the program, the results are summarized in Table 5. These results show that the simple stochastic rotation model under Brown Price and Gompertz wood stock diffusion is a better explanation of the company cut policy, since it only overestimates it in $1.2 \%$. As expected, the Faustmann model has lower optimal cut and underestimate it in $9.2 \%$ and the deterministic optimal cut is even lower, and underestimate the company policy in $27.9 \%$ in the simple case and in $33.1 \%$ in the multiple cases. Finally, the Gompertz wood stock overestimated the Saturation volume in $8.6 \%$.

\section{Conclusions}

1) The optimal cut company policy validates the use of the simple stochastic rotations model under Bown price and Logistic or Gompertz wood stock diffusion.

2) The discrepancy in the theoretical and practical cut policy can be explained by the preference that the business policy gives to shorter rotations periods 25 or less years due to the high organizational risk of the industrial sector in Chile.

3) The Gompertz and Logistic diffusion models present small estimation differences in the growing phase of wood stock, but significant differences in the saturation volume of the wood stock, which should be crucial in the model diffusion selection.

\section{Acknowledgements}

The author acknowledge the collaboration of P. Santibañez of MININCO (2006) forest company for providing with the Radiata pine stands harvest near Temuco and to "Modelo Nacional de Simulación de Pino Radiata" for the complementary stands data of the region.

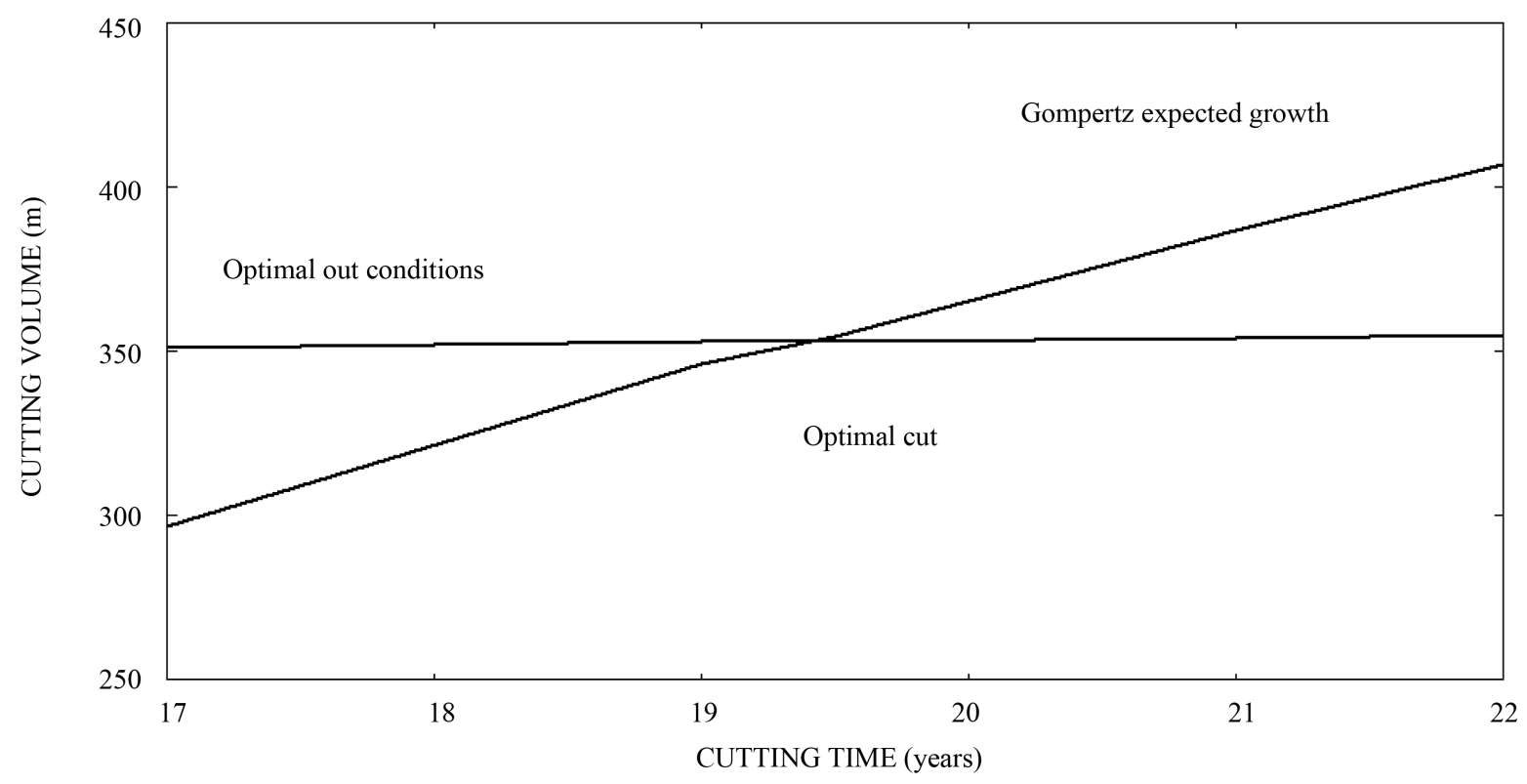

Figure 3. Faustmann gompertz optimal cut.

Table 5. Optimal harvest rotation optimal results, Brown price Gompertz wood stock diffusion.

\begin{tabular}{|c|c|c|c|c|c|c|}
\hline Optimum Policy & $\begin{array}{l}\text { Simple } \\
\mathrm{mts}^{3} / \mathrm{ha}\end{array}$ & Rotation \% & $\begin{array}{l}\text { Multiple } \\
\mathrm{mts}^{3} / \mathrm{ha}\end{array}$ & Rotation \% & $\begin{array}{c}\text { Saturation } \\
\mathrm{mts}^{3} / \mathrm{ha}\end{array}$ & Volume\% \\
\hline Company & 392.9 & 100.0 & 392.9 & 100.0 & 601.6 & 100 \\
\hline Deterministic & 283.2 & -27.9 & 262.8 & -33.1 & & \\
\hline Stochastic & 397.6 & 1.2 & 353.2 & -10.1 & 653.3 & 8.6 \\
\hline
\end{tabular}




\section{References}

Alvarez, L. R., \& Koskela, E. (2007). Optimal Harvesting under Resource Stock and Price Uncertainty. Journal of Economic Dynamics and Control, 31, 2461-2485.

Amacher, G. S., Brazee, R. J., \& Deegan, P. (2011). Faustmann Continues to Yield. Journal of Forest Economics, 17, 231234. http://dx.doi.org/10.1016/j.jfe.2011.06.001

Brazee, R.J. (2001). The Faustmann Formula. Forest Science, 47, 44-49.

Beskos, A., Papaspliopoulos, O., Roberts, G., \& Fearnhead, P. (2006). Exact and Computationally Efficient LikelihoodBased Estimation for Discretely Observed Diffusion Processes (with Discussion). Journal of the Royal Statistical Society: Series B (Statistical Methodology), 68, 333-382.

Chang, S. J. (2001). One Formula Myriad Conclusions, 150 Years of Practicing the Faustmann Formula in Central Europe and the USA. Forest Policy and Economics, 2, 97-99. http://dx.doi.org/10.1016/S1389-9341(01)00053-3

Clarke, H. R., \& Reed, W. J. (1989). The Tree Cutting Problem in a Stochastic Environment. Journal of Economics Dynamic and Control, 13, 569-595. http://dx.doi.org/10.1016/0165-1889(89)90004-3

Faustmann, M. (1995). (Originally 1849). Calculation of the Value which Forest Land and Immature Stands Processess for Forestry. Journal of Forest Economics, 1, 7-44.

Garcia, O. (2005). Unifying Sigmoid Univariate Growth Equations. Forest Biometry, Modelling and Information Sciences (FBMIS), 1, 63-68.

Gaffney, M. M. (1957). Concepts of Financial Maturity of Timber and Other Assets. Agricultural Economics Information Series. Raleigth, NC: North Caroline State College.

Gutierrez, R., Gutierrez-Sanchez, R., \& Nafidi, A. (2008). Modelling and Forecasting Vehicle Stocks Using Trends of Stochastic Gompertz Diffusion Models. Applied Stochastic Models in Business and Industry, 25, 385-405.

Insley, M. (2002). A Real Option Approach to the Valuation of a Forestry on Investment. Journal of Environmental Economics and Management, 44, 471-492.

Insley, M., \& Rollins, K. (2005). On Solving the Multi-Rotational Timber Harvesting Problem with Stochastic Prices: A Linear Complimentarily Formulation. American Journal of Agriculture Economics, 87, 735-755. http://dx.doi.org/10.1111/j.1467-8276.2005.00759.x

Johnson, T. C. (2006). The Optimal Timing of Investment Decisions. PhD Thesis, London: University of London.

Kloeden, P., \& Platen, E. (1992). Numerical Solution of Stochastic Differential Equation (p. 125). Berlin: Springer-Verlag. http://dx.doi.org/10.1007/978-3-662-12616-5

Meyer, P., Yung, J., \& Ausubel, J. (1999). A Primer on Logistic Growth and Substitution: The Mathematics of the Logolet Lab Software. Technological Foresting and Social Change.

MININCO (2006). Santibáñez P. Los Angeles.

Morck, R., \& Schwartz, E. (1989). The Valuation of Forestry Resources under Stochastic Prices and Inventories. Journal of Financial and Quantitative Analysis, 24, 473-487. http://dx.doi.org/10.2307/2330980

Navarrete, E. (2011). Modelling Optimal Pine Stands Harvest under Stochastic Wood Stock and Price in Chile. Forest Policy and Economics, 15, 54-59.

Navarrete, E., \& Bustos, J. (2013). Faustmann Optimal Pine Stands Stochastic Rotation Problem. Forest Policy and Economics, 30, 39-45. http://dx.doi.org/10.1016/j.forpol.2013.02.007

Samuelson, P. (1976). Economics of Forestry in an Evolving Economy. Economic Inquiry, 14, 466-491. http://dx.doi.org/10.1111/j.1465-7295.1976.tb00437.x

Sodal, S. (2002). The Stochastic Rotation Problem: A Comment. Journal of Economics \& Control, 26, 509-515. http://dx.doi.org/10.1016/S0165-1889(00)00076-2

Thijssen, J. J. J. (2010). Irreversible Investment and Discounting: An Arbitrage Pricing Approach. Annals of Finance, 6, 295-315. http://dx.doi.org/10.1007/s10436-008-0108-4

Willassen, Y. (1998). The Stochastic Rotation Problem: A Generalization of Faustmann’s Formula to a Stochastic Forest Growth. Journal of Economic Dynamics and Control, 22, 573-596.

http://dx.doi.org/10.1016/S0165-1889(97)00071-7 
Appendix A: Mininco Radiata Pine Stands Harvest Data

\begin{tabular}{|c|c|c|c|c|c|c|c|c|c|c|}
\hline OT & FECHA_INV & EDAD & DENSIDAD & INDICE_SIT & POD & DEBO & INDUST & COMERC & PULPA & VOLTOT \\
\hline Number & Date & Years & Number & $\mathrm{mts}$ & $\mathrm{mts}^{3} / \mathrm{ha}$ & $\mathrm{mts}^{3} / \mathrm{ha}$ & $\mathrm{mts}^{3} / \mathrm{ha}$ & $\mathrm{mts}^{3} / \mathrm{ha}$ & $\mathrm{mts}^{3} / \mathrm{ha}$ & $\mathrm{mts}^{3} / \mathrm{ha}$ \\
\hline 102809 & 25-01-2005 & 20,069 & 412 & 31,00 & 30,211 & 13,495 & 195,12 & 8,336 & 69,645 & 316,807 \\
\hline 103160 & 08-02-2005 & 20,106 & 305 & 30,60 & 60,217 & 36,52 & 211,321 & 10,159 & 39,562 & 357,779 \\
\hline 102805 & 22-02-2005 & 20,144 & 345 & 31,00 & 43,67 & 15,108 & 178,829 & 10,494 & 55,661 & 303,762 \\
\hline 95972 & 29-08-2004 & 20,664 & 294 & 30,70 & 51,879 & 9,969 & 168,742 & 6,612 & 44,13 & 281,332 \\
\hline 51601 & 09-09-1999 & 20,692 & 406 & 30,40 & 47,735 & 23,134 & 182,41 & 6,609 & 67,564 & 327,452 \\
\hline 51635 & 12-09-1999 & 20,700 & 440 & 30,80 & 49,289 & 33,646 & 247,323 & 9,609 & 77,83 & 417,697 \\
\hline 51691 & 18-09-1999 & 20,717 & 533 & 30,50 & 23,009 & 11,101 & 213,896 & 10,43 & 103,368 & 361,804 \\
\hline 71818 & $15-10-2001$ & 20,792 & 761 & 30,90 & 49,298 & 26,365 & 332,527 & 30,804 & 129,435 & 568,429 \\
\hline 83880 & 15-01-2003 & 21,042 & 299 & 30,70 & 88,091 & 21,753 & 231,1 & 19,339 & 38,159 & 398,442 \\
\hline 84094 & $15-01-2003$ & 21,042 & 359 & 30,90 & 46,783 & 19,625 & 190,715 & 8,831 & 60,556 & 326,510 \\
\hline 102834 & 25-01-2005 & 21,069 & 300 & 30,70 & 66,272 & 10,348 & 191,916 & 8,761 & 45,23 & 322,527 \\
\hline 102744 & 25-01-2005 & 21,069 & 350 & 31,00 & 57,347 & 27,673 & 184,91 & 9,881 & 53,279 & 333,090 \\
\hline 91528 & 30-01-2004 & 21,083 & 323 & 30,60 & 41,753 & 14,123 & 156,805 & 28,112 & 51,448 & 292,241 \\
\hline 75790 & 01-02-2002 & 21,086 & 275 & 30,90 & 89,538 & 34,915 & 150,87 & 29,031 & 35,425 & 339,779 \\
\hline 102865 & 04-02-2005 & 21,094 & 342 & 30,80 & 127,279 & 34,777 & 214,458 & 9,074 & 41,394 & 426,982 \\
\hline 75786 & $13-02-2002$ & 21,119 & 325 & 31,00 & 53,673 & 26,437 & 143,21 & 50,131 & 51,291 & 324,742 \\
\hline 83931 & $16-02-2003$ & 21,128 & 250 & 30,70 & 27,758 & 17,649 & 121,4 & 21,834 & 40,96 & 229,601 \\
\hline 75787 & $16-02-2002$ & 21,128 & 348 & 30,80 & 68,175 & 20,528 & 166,942 & 44,564 & 54,404 & 354,613 \\
\hline 90973 & 23-02-2004 & 21,147 & 393 & 30,60 & 52,687 & 19,955 & 183,955 & 13,828 & 62,824 & 333,249 \\
\hline 76333 & 06-03-2002 & 21,183 & 332 & 30,70 & 77,712 & 23,876 & 165,961 & 72,01 & 46,151 & 385,710 \\
\hline 91641 & 06-03-2004 & 21,183 & 410 & 30,70 & 0,529 & 18,27 & 313,335 & 22,392 & 61,533 & 416,059 \\
\hline 91504 & 08-03-2004 & 21,189 & 294 & 31,00 & 73,553 & 14,884 & 183,809 & 21,771 & 43,984 & 338,001 \\
\hline 91501 & 17-03-2004 & 21,214 & 284 & 31,00 & 79,132 & 13,879 & 187,021 & 15,73 & 39,008 & 334,770 \\
\hline 91151 & 20-03-2004 & 21,231 & 374 & 31,00 & 52,099 & 22,609 & 189,536 & 11,727 & 59,183 & 335,154 \\
\hline 76319 & 24-03-2002 & 21,233 & 236 & 30,80 & 83,656 & 28,056 & 144,961 & 4,015 & 29,774 & 290,462 \\
\hline 91161 & 26-03-2004 & 21,239 & 364 & 30,60 & 20,259 & 15,781 & 169,953 & 9,646 & 63,734 & 279,373 \\
\hline 83406 & 23-01-2003 & 21,639 & 515 & 30,90 & 21,687 & 14,347 & 186,542 & 16,015 & 94,517 & 333,108 \\
\hline 52198 & 16-11-1999 & 21,878 & 1029 & 29,90 & 2,217 & 1,009 & 371,784 & 11,957 & 239,828 & 626,795 \\
\hline 52203 & 22-11-1999 & 21,894 & 609 & 30,30 & 42,256 & 9,958 & 231,214 & 10,5 & 124,584 & 418,512 \\
\hline 63134 & $13-12-2000$ & 21,953 & 342 & 30,10 & 52,596 & 41,286 & 252,125 & 6,077 & 49,345 & 401,429 \\
\hline 74184 & $19-12-2001$ & 21,969 & 279 & 30,60 & 81,005 & 22,015 & 187,372 & 5,492 & 39,47 & 335,354 \\
\hline 66444 & 07-03-2001 & 22,186 & 313 & 30,90 & 89,457 & 9,718 & 208,89 & 6,233 & 49,866 & 364,164 \\
\hline 83886 & 01-02-2003 & 23,086 & 346 & 30,90 & 35,788 & 46,389 & 274,181 & 19,238 & 51,227 & 426,823 \\
\hline 83885 & $19-02-2003$ & 23,136 & 304 & 30,80 & 100,84 & 8,561 & 227,416 & 18,014 & 43,074 & 397,905 \\
\hline 71608 & 03-10-2001 & 23,758 & 800 & 30,90 & 0 & 0 & 338,759 & 42,563 & 146,526 & 527,848 \\
\hline 74494 & $11-12-2001$ & 23,947 & 213 & 30,90 & 77,12 & 15,116 & 204,076 & 7,144 & 28,522 & 331,978 \\
\hline 101906 & 14-01-2005 & 24,039 & 265 & 30,70 & 126,486 & 7,274 & 253,543 & 22,04 & 34,144 & 443,487 \\
\hline
\end{tabular}




\section{Continued}

\begin{tabular}{|c|c|c|c|c|c|c|c|c|c|c|}
\hline 113755 & 29-08-2005 & 24,664 & 672 & 30,60 & 93,303 & 33,622 & 348,677 & 15,913 & 118,159 & 609,674 \\
\hline 87729 & 06-10-2003 & 24,767 & 446 & 30,80 & 4,102 & 1,139 & 446,01 & 20,833 & 74,681 & 546,765 \\
\hline 101738 & 20-01-2005 & 20,056 & 344 & 31,70 & 97,009 & 21,861 & 226,91 & 25,476 & 46,081 & 417,337 \\
\hline 123608 & 20-01-2006 & 20,056 & 447 & 31,70 & 1,289 & 0 & 301,841 & 31,847 & 73,527 & 408,504 \\
\hline 101747 & 26-01-2005 & 20,072 & 310 & 31,80 & 62,756 & 12,844 & 163,095 & 18,867 & 47,627 & 305,189 \\
\hline 101748 & 27-01-2005 & 20,075 & 317 & 31,50 & 67,198 & 13,985 & 168,31 & 28,119 & 56,473 & 334,085 \\
\hline 123355 & 28-01-2006 & 20,078 & 890 & 31,70 & 0 & 0 & 340,058 & 43,398 & 154,206 & 537,662 \\
\hline 101749 & 01-02-2005 & 20,086 & 295 & 31,30 & 54,651 & 14,83 & 172,718 & 10,396 & 43,363 & 295,958 \\
\hline 102750 & 05-02-2005 & 20,097 & 339 & 31,40 & 83,138 & 29,424 & 191,109 & 7,36 & 45,999 & 357,030 \\
\hline 123632 & 06-02-2006 & 20,100 & 357 & 31,90 & 142,767 & 29,785 & 237,26 & 9,796 & 46,357 & 465,965 \\
\hline 123226 & 09-02-2006 & 20,108 & 502 & 31,10 & 41,176 & 44,536 & 276,147 & 19,468 & 74,52 & 455,847 \\
\hline 123635 & 23-02-2006 & 20,147 & 300 & 31,20 & 114,971 & 20,195 & 193,637 & 10,067 & 39,382 & 378,252 \\
\hline 103466 & 24-02-2005 & 20,150 & 339 & 32,00 & 40,519 & 37,1 & 217,016 & 21,458 & 51,34 & 367,433 \\
\hline 48607 & 04-03-1999 & 20,178 & 397 & 31,20 & 68,764 & 12,871 & 227,406 & 6,839 & 63,118 & 378,998 \\
\hline 48597 & 18-03-1999 & 20,217 & 448 & 31,40 & 85,781 & 18,874 & 250,142 & 6,616 & 68,97 & 430,383 \\
\hline 48606 & 23-03-1999 & 20,231 & 547 & 31,50 & 74,666 & 14,134 & 270,051 & 8,732 & 93,449 & 461,032 \\
\hline 48611 & 05-04-1999 & 20,264 & 395 & 31,90 & 77,063 & 14,042 & 235,185 & 8,001 & 68,931 & 403,222 \\
\hline 48627 & 06-04-1999 & 20,267 & 420 & 31,40 & 57,08 & 15,927 & 220,74 & 6,045 & 75,991 & 375,783 \\
\hline 48636 & 15-04-1999 & 20,292 & 326 & 31,40 & 95,803 & 10,146 & 215,994 & 6,66 & 69,367 & 397,970 \\
\hline 95971 & 27-08-2004 & 20,658 & 328 & 31,90 & 55,705 & 11,822 & 200,075 & 8,366 & 51,535 & 327,503 \\
\hline 98360 & 26-09-2004 & 20,739 & 351 & 31,90 & 91,606 & 10,282 & 235,839 & 34,439 & 51,152 & 423,318 \\
\hline 47911 & 22-12-1998 & 20,978 & 785 & 31,40 & 32,303 & 16,294 & 258,41 & 19,006 & 194,812 & 520,825 \\
\hline 47912 & 23-12-1998 & 20,981 & 629 & 31,40 & 38,985 & 11,536 & 237,974 & 14,113 & 152,54 & 455,148 \\
\hline 101575 & 13-01-2005 & 21,036 & 404 & 32,00 & 92,721 & 14,187 & 255,165 & 16,403 & 62,515 & 440,991 \\
\hline 102567 & $17-01-2005$ & 21,047 & 417 & 31,10 & 103,542 & 18,677 & 241,928 & 16,069 & 60 & 440,216 \\
\hline 101744 & 19-01-2005 & 21,053 & 406 & 31,80 & 88,98 & 11,174 & 255,961 & 12,042 & 64,296 & 432,453 \\
\hline 102563 & 20-01-2005 & 21,056 & 469 & 31,30 & 88,279 & 31,801 & 258,86 & 21,657 & 69,483 & 470,080 \\
\hline 102747 & 21-01-2005 & 21,058 & 360 & 31,30 & 46,999 & 26,463 & 194,858 & 8,788 & 57,079 & 334,187 \\
\hline 101573 & 21-01-2005 & 21,058 & 333 & 32,00 & 55,895 & 13,776 & 192,788 & 17,102 & 53,577 & 333,138 \\
\hline 101745 & 24-01-2005 & 21,067 & 372 & 31,70 & 80,019 & 14,1 & 245,135 & 10,045 & 57,013 & 406,312 \\
\hline 101574 & 25-01-2005 & 21,069 & 333 & 31,30 & 70,24 & 20,794 & 203,195 & 24,886 & 56,044 & 375,159 \\
\hline 101833 & 27-01-2005 & 21,075 & 317 & 31,20 & 110,331 & 6,772 & 196,835 & 47,767 & 44,234 & 405,939 \\
\hline 91460 & 27-01-2004 & 21,075 & 279 & 31,30 & 86,05 & 33,086 & 188,059 & 18,132 & 37,383 & 362,710 \\
\hline 91467 & 27-01-2004 & 21,075 & 358 & 31,30 & 42,62 & 18,72 & 199,167 & 19,963 & 57,223 & 337,693 \\
\hline 91529 & 29-01-2004 & 21,081 & 315 & 31,10 & 53,811 & 10,9 & 161,087 & 31,303 & 50,264 & 307,365 \\
\hline 91465 & 29-01-2004 & 21,081 & 274 & 31,20 & 82,99 & 10,868 & 192,224 & 8,701 & 39,322 & 334,105 \\
\hline 75796 & 31-01-2002 & 21,086 & 317 & 31,80 & 75,935 & 28,873 & 170,227 & 8,407 & 49,172 & 332,614 \\
\hline 102824 & 02-02-2005 & 21,089 & 290 & 31,80 & 64,403 & 9,414 & 172,096 & 26,284 & 47,789 & 319,986 \\
\hline 75887 & 09-02-2002 & 21,108 & 368 & 31,30 & 52,133 & 21,99 & 179,072 & 7,763 & 61,943 & 322,901 \\
\hline 103461 & 09-02-2005 & 21,108 & 297 & 31,90 & 82,518 & 15,045 & 203,406 & 30,78 & 40,854 & 372,603 \\
\hline
\end{tabular}




\section{Continued}

\begin{tabular}{|c|c|c|c|c|c|c|c|c|c|c|}
\hline 75889 & $10-02-2002$ & 21,111 & 348 & 31,40 & 63,778 & 27,662 & 180,999 & 6,773 & 56,997 & 336,209 \\
\hline 90970 & $17-02-2004$ & 21,131 & 428 & 32,00 & 56,244 & 16,199 & 198,662 & 18,414 & 68,095 & 357,614 \\
\hline 102833 & 22-02-2005 & 21,144 & 373 & 31,30 & 71,751 & 19,283 & 229,216 & 8,982 & 56,629 & 385,861 \\
\hline 102832 & 23-02-2005 & 21,147 & 377 & 31,80 & 64,873 & 16,667 & 230,532 & 9,745 & 60,034 & 381,851 \\
\hline 91308 & 15-03-2004 & 21,208 & 333 & 31,40 & 7,169 & 35,563 & 195,655 & 108,045 & 50,411 & 396,843 \\
\hline 91152 & $15-03-2004$ & 21,208 & 290 & 32,00 & 96,706 & 33,638 & 184,155 & 9,495 & 39,262 & 363,256 \\
\hline 91508 & $17-03-2004$ & 21,214 & 277 & 31,90 & 83,842 & 21,53 & 175,696 & 10,507 & 40,067 & 331,642 \\
\hline 91138 & 19-03-2004 & 21,219 & 352 & 31,10 & 43,032 & 24,143 & 213,379 & 11,063 & 51,024 & 342,641 \\
\hline 91499 & 19-03-2004 & 21,219 & 354 & 31,70 & 60,3 & 23,848 & 193,449 & 12,761 & 56,861 & 347,219 \\
\hline 76314 & 21-03-2002 & 21,225 & 295 & 31,10 & 83,129 & 29,704 & 168,314 & 6,804 & 39,028 & 326,979 \\
\hline 91150 & 30-03-2004 & 21,250 & 335 & 31,10 & 54,334 & 28,177 & 137,598 & 74,463 & 49,396 & 343,968 \\
\hline 52202 & 20-11-1999 & 21,889 & 1000 & 31,30 & 0 & 0 & 375,916 & 11,432 & 192,103 & 579,451 \\
\hline 52204 & 26-11-1999 & 21,906 & 915 & 31,20 & 0 & 0 & 271,492 & 10,512 & 213,957 & 495,961 \\
\hline 56179 & $14-03-2000$ & 22,206 & 546 & 31,70 & 89,278 & 20,81 & 305,403 & 8,982 & 99,265 & 523,738 \\
\hline 83523 & 17-01-2003 & 23,047 & 211 & 31,40 & 77,772 & 4,129 & 153,92 & 32,647 & 31,203 & 299,671 \\
\hline 75661 & 05-02-2002 & 23,097 & 298 & 31,10 & 153,673 & 8,138 & 284,036 & 53,474 & 36,826 & 536,147 \\
\hline 76843 & $12-03-2002$ & 23,200 & 550 & 31,90 & 60,901 & 22,524 & 322,74 & 40,764 & 98,317 & 545,246 \\
\hline 96629 & 26-08-2004 & 24,656 & 222 & 31,60 & 109,406 & 14,078 & 239,825 & 13,152 & 26,738 & 403,199 \\
\hline 96628 & 28-08-2004 & 24,661 & 221 & 32,00 & 110,83 & 10,141 & 242,607 & 10,845 & 27,866 & 402,289 \\
\hline 96630 & 30-08-2004 & 24,667 & 225 & 31,60 & 92,591 & 10,419 & 195,494 & 27,384 & 30,712 & 356,600 \\
\hline 81275 & 25-09-2002 & 24,736 & 447 & 31,30 & 26,623 & 52,339 & 418,624 & 23,667 & 68,454 & 589,707 \\
\hline 114503 & $15-09-2005$ & 25,708 & 347 & 31,50 & 85,776 & 30,121 & 316,837 & 13,993 & 48,589 & 495,316 \\
\hline 101751 & 11-01-2005 & 20,031 & 313 & 32,10 & 100,369 & 9,866 & 200,563 & 22,615 & 44,89 & 378,303 \\
\hline 101746 & 19-01-2005 & 20,053 & 303 & 32,40 & 55,155 & 11,971 & 171,863 & 27,424 & 47,264 & 313,677 \\
\hline 101753 & 20-01-2005 & 20,061 & 290 & 32,10 & 100,957 & 10,857 & 197,157 & 7,7 & 40,732 & 357,403 \\
\hline 103162 & 25-01-2005 & 20,069 & 363 & 34,50 & 0 & 0 & 308,817 & 43,479 & 62,114 & 414,410 \\
\hline 102765 & 02-02-2005 & 20,089 & 359 & 33,10 & 43,378 & 20,648 & 215,688 & 13,047 & 60,672 & 353,433 \\
\hline 103465 & 23-02-2005 & 20,147 & 324 & 32,70 & 35,602 & 33,756 & 213,888 & 43,265 & 49,633 & 376,144 \\
\hline 127213 & 25-02-2006 & 20,153 & 312 & 32,30 & 61,569 & 15,948 & 125,533 & 73,06 & 45,674 & 321,784 \\
\hline 124619 & $25-02-2006$ & 20,153 & 414 & 35,10 & 0 & 0 & 304,078 & 23,043 & 93,149 & 420,270 \\
\hline 48637 & 13-04-1999 & 20,286 & 438 & 33,70 & 109,062 & 17,36 & 298,884 & 8,893 & 80,999 & 515,198 \\
\hline 48633 & 16-04-1999 & 20,294 & 386 & 32,10 & 75,26 & 16,378 & 304,09 & 6,758 & 61,994 & 464,480 \\
\hline 95970 & $30-08-2004$ & 20,667 & 299 & 32,90 & 62,127 & 14,75 & 211,774 & 8,368 & 44,546 & 341,565 \\
\hline 98361 & 28-09-2004 & 20,745 & 383 & 32,50 & 78,934 & 9,75 & 262,531 & 30,704 & 57,672 & 439,591 \\
\hline 101740 & 07-01-2005 & 21,019 & 435 & 32,20 & 90,006 & 12,714 & 267,781 & 22,698 & 72,831 & 466,030 \\
\hline 83405 & $16-01-2003$ & 21,045 & 339 & 32,20 & 46,08 & 22,387 & 180,907 & 13,669 & 58,606 & 321,649 \\
\hline 102843 & 18-01-2005 & 21,050 & 296 & 33,00 & 110,036 & 13,61 & 258,581 & 10,547 & 39,962 & 432,736 \\
\hline 102795 & 19-01-2005 & 21,053 & 454 & 32,20 & 33,334 & 10,63 & 235,047 & 9,416 & 82,856 & 371,283 \\
\hline 75754 & 08-02-2002 & 21,106 & 421 & 34,20 & 93,435 & 9,237 & 280,858 & 21,142 & 69,074 & 473,746 \\
\hline 84120 & $15-02-2003$ & 21,125 & 259 & 34,80 & 80,143 & 12,525 & 181,992 & 66,744 & 38,426 & 379,830 \\
\hline
\end{tabular}




\section{Continued}

\begin{tabular}{ccccccccccc}
\hline 54835 & $26-02-2000$ & 21,156 & 335 & 32,90 & 72,231 & 12,019 & 217,648 & 7,542 & 72,837 & 382,277 \\
112964 & $04-08-2005$ & 21,594 & 552 & 33,20 & 51,201 & 18,57 & 253,839 & 52,399 & 97,698 & 473,707 \\
62236 & $27-09-2000$ & 21,742 & 400 & 32,10 & 122,383 & 20,963 & 310,676 & 10,81 & 76,532 & 541,364 \\
81497 & $30-09-2002$ & 21,750 & 299 & 32,90 & 0,999 & 50,428 & 316,128 & 14,549 & 40,111 & 422,215 \\
83616 & $21-02-2003$ & 22,142 & 292 & 32,50 & 87,783 & 26,583 & 194,151 & 29,612 & 41,126 & 379,255 \\
74324 & $15-12-2001$ & 22,958 & 347 & 32,70 & 71,151 & 28,513 & 177,427 & 49,93 & 61,445 & 388,466 \\
75955 & $22-02-2002$ & 23,144 & 236 & 32,10 & 103,693 & 38,456 & 183,181 & 5,162 & 30,643 & 361,135 \\
103438 & $24-02-2005$ & 24,150 & 260 & 35,00 & 27,641 & 59,521 & 352,155 & 18,261 & 35,659 & 493,237 \\
76837 & $18-03-2002$ & 24,217 & 515 & 32,20 & 16,069 & 8,318 & 468,02 & 8,436 & 79,23 & 580,073 \\
124604 & $28-02-2006$ & 25,161 & 347 & 32,10 & 111,71 & 41,25 & 255,813 & 18,786 & 52,947 & 480,506 \\
\hline
\end{tabular}

Notes: TVOL $=$ Total Volume $(\mathrm{mts} 3 / \mathrm{ha}) ;$ TVOL $=$ POD + DEBO + INDUST + COMERC + PULPA POD + DEBO = Wood thinning cuts; Logs composition: Saw logs = INDUST + COMERC = 83.9\%; Pulp logs = PULP + POD + DEBO = 16.1\%; Saturation volume Vs $=601.6 \mathrm{~m}^{3} / \mathrm{ha},(3 \%$ stands biggest TVOL average).

\section{Appendix B: Radiata Pine Log Prices}

Table B1. Nominal Radiata Pine log exportation prices.

\begin{tabular}{|c|c|c|c|c|c|}
\hline YEARS & Saw logs & Pulp logs & YEARS & Saw logs & Pulp logs \\
\hline & $\mathrm{US} \$ / \mathrm{mts}^{3}$ & US $\$ / \mathrm{mts}^{3}$ & & $\mathrm{US} \$ / \mathrm{mts}^{3}$ & $\mathrm{US} \$ / \mathrm{mts}^{3}$ \\
\hline 1985 & 32.0 & 27.0 & 1997 & 62.0 & 55.0 \\
\hline 1986 & 34.0 & 28.0 & 1998 & 52.0 & 54.0 \\
\hline 1987 & 39.0 & 27.0 & 1999 & 49.0 & 53.0 \\
\hline 1988 & 45.0 & 27.0 & 2000 & 46.0 & 42.0 \\
\hline 1989 & 43.0 & 27.0 & 2001 & 48.0 & 34.0 \\
\hline 1990 & 49.0 & 32.0 & 2002 & 46.0 & 41.6 \\
\hline 1991 & 51.0 & 40.0 & 2003 & 45.9 & 37.4 \\
\hline 1992 & 47.0 & 40.0 & 2004 & 48.6 & 33.0 \\
\hline 1993 & 85.0 & 38.0 & 2005 & 57.0 & 33.5 \\
\hline 1994 & 63.0 & 46.0 & 2006 & 60.0 & 36.0 \\
\hline 1995 & 67.0 & 43.0 & 2007 & 63.0 & 40.0 \\
\hline 1996 & 65.0 & 52.0 & & & \\
\hline
\end{tabular}

Source CONAF-INFOR Chile.

The Price diffusion parameters can very easily be calculated by making the following logarithmic transformation $p_{t}=\ln \left(p_{t} / p_{t-1}\right)$. The parameters are given by Table $\mathbf{B} 2$.

$$
\alpha=\bar{p}=\sum \frac{p_{t}}{n}=\left(\alpha-\sigma^{2} / 2\right), \beta^{2}=\sum \frac{\left(p_{t}-\bar{p}\right)^{2}}{n-1}
$$

Table B2. Log summary.

\begin{tabular}{cccc}
\hline Summary & Stumpage logs & Saw logs & Pulp logs \\
\hline Percentage & $100 \%$ & 83.9 & 16.1 \\
Price drift $\alpha$ & $2.9 \%$ & 3.08 & 1.79 \\
Price volatility $\beta$ & $15.9 \%$ & 16.52 & 12.74 \\
Average Price & 39.74 & & \\
\hline
\end{tabular}

